\title{
Pregnancy-related comorbidities and labor induction - the effectiveness and safety of dinoprostone compared to misoprostol
}

\author{
Teresa Gornisiewicz ${ }^{1}$, Hubert Huras ${ }^{2}$ (D), \\ Katarzyna Kusmierska-Urban²*(1), Aleksander Galas ${ }^{3}$ (i) \\ ${ }^{1}$ Department of Obstetrics and Perinatology, University Hospital, Cracow, Poland \\ ${ }^{2}$ Department of Obstetrics and Perinatology, Jagiellonian University Medical College, Cracow, Poland \\ ${ }^{3}$ Chair of Epidemiology and Preventive Medicine, Jagiellonian University Medical College, Cracow, Poland \\ *employed until 2019
}

\begin{abstract}
Objectives: The aim of the study was to evaluate whether the presence of the disease in pregnancy influences the effectiveness and safety of delivery preinduction with prostaglandins: misoprostol vaginal insert and dinoprostone vaginal gel. Material and methods: This is a retrospective cohort study conducted of 560 pregnant women. The concomitant diseases mainly recorded were diabetes mellitus, hypertensive diseases, intrahepatic cholestasis of pregnancy, asthma, thrombocytopenia, and hypothyroidism. The primary study outcome was a successful vaginal delivery. The study above others evaluates the time from treatment implementation to the beginning of a labor and to a final delivery, the rate of Cesarean sections, and the presence of delivery complications.

Results: Among women with a concomitant disease, Caesarean section was observed more frequently in the misoprostol group. In the dinoprostone group, mothers with the concomitant disease as compared to healthy mothers required more time to the delivery and to achieve the beginning of labor. There were no differences in postpartum complications regardless of the prostaglandins, comorbidities or mothers' age. Neonates of mothers $\geq 35$ years old with concomitant disease had lower average Apgar scores.

Conclusions: Our study showed that comorbidities seem to increase the caesarean section risk in the misoprostol preinduction group but in the dinoprostone group they prolong the time needed to achieve an active labour phase and a delivery. Key words: comorbidities; dinoprostone; labor induction; misoprostol
\end{abstract}

Ginekologia Polska 2021; 92, 9: 647-658

\section{INTRODUCTION}

In the era of postponing pregnancy to an advanced age of women, which has both social and economic determinants, various consequences of such decisions must be considered. Among older pregnant women, especially over 40 years old, the risk of comorbidities increases [1].

Hypertension in pregnancy concerns $6-10 \%$ of pregnancies [2, 3]. It is associated with numerous complications during pregnancy $[4,5]$. The delivery beyond 37 weeks' gestation in pregnancies with the mild hypertensive disease was associated with improved maternal outcomes [6]. It has been proven, that labour induction at 38 or 39 weeks in pregnant women with uncomplicated chronic hypertension appears to reduce the risk of serious neonatal morbidity and mortality [7].

It is well known that diabetes type Il is highly correlated with obesity and unfortunately obesity among women of reproductive age (20-39 years) increases, which altogether is concerning [8-9]. Obesity is a popular risk factor for stillbirth [10]. Fetal hypertrophy may lead to a disproportion of labour, shoulder dystocia during delivery, the need for urgent caesarean section with an increased risk of preoperative complications [11]. Both maternal gestational diabetes mellitus and obesity are independently associated with an unfavourable course of pregnancy and both have an even greater impact than either one alone [12]. In order

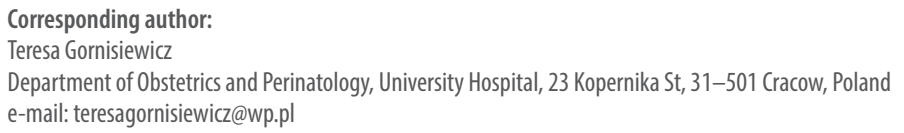


to reduce the risk of fetal complications in pregnancy with pregestational diabetes and gestational diabetes, Polish Gynaecological Society recommends labour induction after 38 weeks and after 39 weeks of gestation, respectively [13].

Pregnant women older than 35 years have also increased risk of placenta previa, placental abruption or preterm birth and small-for-gestational age neonates. When comparing the adjusted perinatal mortality rates between women aged 20-24 with 35-39 and 40 years old, the rates were $63 \%$ $(p=0.04)$ and $183 \%(p=0.01)$, respectively. Also, the rates of the adjusted perinatal mortality and morbidity rates were much higher in over 35 years-old pregnant group comparing with women under 25 years old [14]. There is the real risk of stillbirth in pregnant women aged 40 and more and that is why The Polish Society of Gynecologists and Obstetricians recommends to treat those pregnancies as biologically mature and to induct labour at 39 weeks of gestation [13].

As mentioned above there are studies showing the need for active rather than expectant management according to varies pregnancy complications and finishing the pregnancy before 40 weeks of gestation. The choice of the method, in accordance with the recommendations of The Polish Society of Gynecologists and Obstetricians, is based mainly on the assessment of obstetric state in each patient, the preferences of the deciding physician and, most often, the availability of a given procedure in a hospital.

The crucial role plays the maturity of the cervix mostly assessed by scale introduced by Bishop in 1964 [15]. There are many possible ways of preparing the cervix to the delivery which is called a labour pre-induction. The most often used ones include the mechanical ways (a Foley or a double-balloon catheter, membrane stripping) and the pharmacological way with the usage of prostaglandins in a numerous dosage and routs of administration (dinoprostone-prostaglandin E2 and misoprostol-prostaglandin E1) [16].

Available research results show effectiveness and safety of a use of prostaglandins for preinduction purposes, after a control for several covariates, and, as mentioned above, there are several clinical characteristics of the pregnant woman which are indications for the use of preinduction. The knowledge, however, on how the presence of a disease in pregnant woman influences clinical outcomes in those patients is very limited.

\section{Objectives}

The aim of the study was to evaluate whether the presence of the disease in pregnancy influences the effectiveness and safety of prostaglandins which are the most often used in routine clinical practice for preinduction, meaning: the misoprostol vaginal insert at a dose of $0.2 \mathrm{mg}$ (Misodel, Ferring Pharmaceuticals Poland sp.z o.o) and dinoprostone gel at a dose of $0.5 \mathrm{mg}$ (Prepidil, Pfizer Polska Sp. z o.o.). In details, the study assessed whether the presence of disease influences the effectiveness of the two aforementioned drugs measured by the time from treatment implementation to the beginning of a labour and to a final delivery and safety measured by the rate of emergency Caesarean sections, the presence of delivery complications, and some health indicators in newborns. Additionally, we addressed an issue of mothers' age as a potential contributing factor.

\section{MATERIAL AND METHODS}

The study included 560 pregnant women hospitalized at the Obstetric and Perinatology Department at the University Hospital in Cracow between January 2015 and April 2019. This was a retrospective cohort design for which all available medical records had been identified and reviewed. The list of collected information covered among others: maternal age, body mass index (BMI), number of pregnancies, parity history, gestational age. The mode of delivery, indications for caesarean section and other maternal outcomes including, episiotomy, anemia requiring blood transfusion, uterine hyperstimulation were also counted.

All patients identified as eligible for the study had to have singleton gestation with cephalic presentation and they required labour induction for medical indications. The cervical ripening was performed with dinoprostone gel or misoprostol insert. There were no known selection rules implemented by physicians at a clinic which might favor the use of one drug over the other due to patient's characteristics or preferences. Other inclusion criteria were the Bishop's score $\leq 4$ and an absence of an active labour before administration of the drug. Exclusions included expected fetal weight over $4500 \mathrm{~g}$ or any known contraindication to vaginal delivery, or any contraindication for prostaglandins. For the presented study, pregnant women with any diagnosed disease were included. These were mainly: any tape of diabetes mellitus, hypertensive diseases, intrahepatic cholestasis of pregnancy, asthma and thrombocytopenia, hypothyroidism.

The primary study outcome was a successful vaginal delivery. Secondary effectiveness outcome measures were time from drug administration to delivery (both, vaginal and Caesarean section), induction-active labour interval time and durations of the first three delivery stages. The safety outcomes covered any complication observed during a labor such as blood transfusion, uterine hyperstimulation, curettage after delivery, episiotomy, rupture of perineum, and additionally emergency Caesarean delivery.

\section{Statistical analysis}

For the purpose of the study, all participants have been classified into two groups, a dinoprostone and 
a misoprostol group. The categorization was made by the implementation of the intention to treat (ITT) principle. Thusly, mothers who were intended to begin their labour with dinoprostone and received dinoprostone as a first drug after admission were categorized as dinoprostone group members, and those who received misoprostol first composed a misoprostol group. There was also a group of women, in which, in the lack of effect of one drug, the other had been implemented. These were included according to the intention to treat (ITT) criteria in the appropriate group in the effectiveness analyses and additionally were analyzed as a separate group when complications were considered.

The descriptive characteristics of the investigated groups have been presented by the mean, SD, median and first (Q1) and third quartile (Q3). Median and quartiles were used as majority of data distributions were skewed causing the mean and SD were not informative enough to provide appropriate group depiction. To test whether there were differences in the study outcomes across analyzed groups the following strategy had been implemented for categorical data: 1. a chi-square test was used provided the expected values exceeded 5 , otherwise, the Fisher's exact test was used; 2 . to test whether there is a difference between mothers with a disease as compared to mothers without a disease across strata by mother's age (< 35 yrs vs 35 + yrs) the Cochran-Mantel-Haenszel statistics were used. This answered a question of whether the effect size caused by the presence of a disease across the two treatments differed between younger and older mothers. For continuous data: 1. firstly, the assumption of normal distribution had been tested using Shapiro-Wilk test; 2 . as the variables analyzed were skewed the U-Mann-Whitney test was used to test for significance of a difference. The results with a $p<0.05$ were considered statistically significant. The pairwise procedure was used for missing data, consequently all the available data were used for analyses. All analyses had been made by the IBM SPSS Statistics, version 26

\section{RESULTS}

There were 560 women identified as admitted for a labour induction in the calendar period covered by the study. In this group, the misoprostol insert was applied to 210 pregnant women, and dinoprostone gel was used in 350 patients. In the dinoprostone group 100 women, who received additionally misoprostol as a second drug, were identified. In total, there were 320 women with at least one diagnosed disease 117 in the misoprostol and 203 in the dinoprostone group. Out of these 57 and 87, respectively, were diagnosed with hypothyroidism, 27 and 28 with hypertension, 23 and 65 had diabetes, 3 and 15 had both, diabetes and hypertension, and 7 and 8 had some other diseases. Women diagnosed with any concomitant disease had higher body mass and higher BMI in both dinoprostone and misoprostol groups. Women representing $35+$ age category characterized a higher number of pregnancies. All the other characteristics were similar across analyzed groups (Tab. 1 and 2).

Among women with concomitant disease vaginal delivery was observed more frequently in the dinoprostone group as compared to misoprostol (66.5\% vs $52.1 \%$, $p=0.013$ ). Consequently, Caesarean sections were observed more frequently in the misoprostol group. Moreover, mothers with a disease treated by misoprostol as compared to dinoprostone more frequently were referred to Caesarean section in emergency (Tab. 3). When we took into account the misoprostol group only, a higher proportion of pregnant women with a concomitant disease (as compared to women without the disease) underwent Caesarean section (47.9\% vs $31.2 \% ; p=0.016$ ), and also more of them experienced emergency Caesarean section (being a part out of total deliveries) (35.9\% vs $20.4 \%$; respectively, $p=0.015$ ). Those differences were not observed in the dinoprostone group (Tab. 3). Some detailed analysis of Caesarean indications revealed that pregnant women with a disease treated by misoprostol more frequently presented preeclampsia and placenta abruption (both, when they were compared with mothers with a disease treated by dinoprostone, and with mothers treated by misoprostol but having no concomitant disease) (Tab. 3).

There were no differences in postpartum complications in the group of study participants regardless of the prostaglandin combination, any concomitant disease, or mothers' age, apart from more often need for episiotomy and an occurrence of rupture of perineum in dinoprostone group. (Tab. 4a and 4b).

Interesting findings are shown in Table 5 with time intervals from drug implementation to delivery (vaginal only or any delivery). It has been observed that in the group treated by dinoprostone, mothers with the concomitant disease as compared to mothers without the disease required more time to the delivery (vaginal route only: 39.6 vs 31.3 hours, $p=0.014$, or any rout: 42.8 vs 35.6 hours, $p=0.023$ ) and to achieve the beginning of a labor (33.5 vs $25.3, p=0.009$ ). After analysis of mothers' age, we have found no differences. In the misoprostol group, no significant differences in time intervals were found. The investigation of dinoprostone - misoprostol differences analyzed in the concomitant disease group we noticed that the time from the drug implementation to the onset of regular contraction activity of the uterus and to the delivery of the newborn was shorter for misoprostol as compared to dinoprostone and the differences were statistically significant (Tab. 5). 
Table 1. Clinical characteristics of the study "ITT dinoprostone group" across study participants

\begin{tabular}{|c|c|c|c|c|c|c|}
\hline & \multicolumn{3}{|c|}{ No concomitant disease } & \multicolumn{3}{|c|}{ Any concomitant disease } \\
\hline & $\begin{array}{l}\text { Whole group } \\
{[n=147]}\end{array}$ & $\begin{array}{l}\text { Mothers < } 35 y \\
{[n=119]}\end{array}$ & $\begin{array}{l}\text { Mothers } 35+ \\
{[n=28]}\end{array}$ & $\begin{array}{l}\text { Whole group } \\
{[n=203]}\end{array}$ & $\begin{array}{l}\text { Mothers < } 35 y \\
{[n=164]}\end{array}$ & $\begin{array}{l}\text { Mothers } 35+ \\
{[n=39]}\end{array}$ \\
\hline $\begin{array}{l}\text { Maternal age [years] } \\
\text { Mean (SD) } \\
\text { Median (Q1-Q3) }\end{array}$ & $\begin{array}{l}30.4(4.7) \\
30.0(28.0-34.0)\end{array}$ & $\begin{array}{l}28.7(3.5) \\
29.0(27.0-31.0)\end{array}$ & $\begin{array}{l}37.4(2.3) \\
37.0(36.0-38.9)\end{array}$ & $\begin{array}{l}30.6(4.4) \\
30.0(28.0-33.0)\end{array}$ & $\begin{array}{l}29.1(3.2) \\
29.0(27.0-32.0)\end{array}$ & $\begin{array}{l}37.0(2.1) \\
37.0(35.0-38.0)\end{array}$ \\
\hline $\begin{array}{l}\text { Weight at admission [kg] } \\
\text { Mean (SD) } \\
\text { Median (Q1-Q3) }\end{array}$ & $\begin{array}{l}{[n=83]} \\
78.1(12.6) \\
76.0(69.0-85.0)\end{array}$ & $\begin{array}{l}{[n=64]} \\
77.9(12.2) \\
74.9(68.6-84.8)\end{array}$ & $\begin{array}{l}{[n=19]} \\
78.9(14.2) \\
78.0(70.0-88.0)\end{array}$ & $\begin{array}{l}{[n=113]} \\
81.3(14.7) \\
79.0(71.5-89.0)\end{array}$ & $\begin{array}{l}{[n=90]} \\
80.9(15.1) \\
79.0(70.8-89.0)\end{array}$ & $\begin{array}{l}{[n=23]} \\
82.7(13.2) \\
80.0(72.0-94.0)\end{array}$ \\
\hline $\begin{array}{l}\text { Height }[\mathrm{cm}] \\
\text { Mean (SD) } \\
\text { Median (Q1-Q3) }\end{array}$ & $\begin{array}{l}{[n=130]} \\
167.2(5.9) \\
168.0 \\
(164.0-171.0)\end{array}$ & $\begin{array}{l}{[n=103]} \\
167.9(5.6) \\
168.0 \\
(164.0-172.0)\end{array}$ & $\begin{array}{l}{[n=27]} \\
164.6(6.6) \\
165.0 \\
(160.0-170.0)\end{array}$ & $\begin{array}{l}{[n=182]} \\
165.6(6.3) \\
165.0 \\
(161.8-170.0)\end{array}$ & $\begin{array}{l}{[n=147]} \\
165.7(6.3) \\
165.0 \\
(162.0-170.0)\end{array}$ & $\begin{array}{l}{[n=35]} \\
164.9(6.0) \\
165.0 \\
(160.0-170.0)\end{array}$ \\
\hline $\begin{array}{l}\text { Body mass index at admission } \\
{\left[\mathrm{kg} / \mathrm{m}^{2}\right]} \\
\text { Mean (SD) } \\
\text { Median (Q1-Q3) }\end{array}$ & $\begin{array}{l}{[n=83]} \\
27.7(4.1) \\
27.1(24.9-30.4)\end{array}$ & $\begin{array}{l}{[n=64]} \\
27.3(3.7) \\
26.3(24.7-29.3)\end{array}$ & $\begin{array}{l}{[n=19]} \\
29.4(4.9) \\
30.1(26.7-31.9)\end{array}$ & $\begin{array}{l}{[n=113]} \\
29.8(4.8) \\
29.7(25.9-32.1)\end{array}$ & $\begin{array}{l}{[n=90]} \\
29.6(4.9) \\
29.7(25.3-32.1)\end{array}$ & $\begin{array}{l}{[n=23]} \\
30.8(4.4) \\
30.4(27.7-33.3)\end{array}$ \\
\hline \multicolumn{7}{|l|}{ Number of pregnancies, n (\%) } \\
\hline 1 & $97(66.0 \%)$ & $89(74.8 \%)$ & $8(28.6 \%)$ & $130(64.0 \%)$ & $113(68.9 \%)$ & $17(43.6 \%)$ \\
\hline 2 & $27(18.4 \%)$ & $20(16.8 \%)$ & $7(25.0 \%)$ & $47(23.2 \%)$ & $37(22.6 \%)$ & $10(25.6 \%)$ \\
\hline$\geq 3$ & $23(15.6 \%)$ & $10(8.4 \%)$ & $13(46.4 \%)$ & $26(12.8 \%)$ & $14(8.5 \%)$ & $12(30.8 \%)$ \\
\hline \multicolumn{7}{|c|}{ Parity history (current delivery included), n (\%) } \\
\hline 1 & $112(76.2 \%)$ & $99(83.2 \%)$ & $13(46.4 \%)$ & $155(76.4 \%)$ & $134(81.7 \%)$ & $21(53.8 \%)$ \\
\hline 2 & $24(16.3 \%)$ & $17(14.3 \%)$ & $7(25.0 \%)$ & $34(16.7 \%)$ & $25(15.2 \%)$ & $9(23.1 \%)$ \\
\hline$\geq 3$ & $11(7.5 \%)$ & $3(2.5 \%)$ & $8(28.6 \%)$ & $14(6.9 \%)$ & $5(3.0 \%)$ & $9(23.1 \%)$ \\
\hline Nulliparous, n (\%) & $111(75.5 \%)$ & $100(84.0 \%)$ & $11(39.3 \%)$ & $151(74.4 \%)$ & $129(78.7 \%)$ & $22(56.4 \%)$ \\
\hline \multicolumn{7}{|l|}{ Miscarriage history, n (\%) } \\
\hline no & $120(81.6 \%)$ & $103(86.6 \%)$ & $17(60.7 \%)$ & $169(83.3 \%)$ & $137(83.5 \%)$ & $32(82.1 \%)$ \\
\hline yes & $27(18.4 \%)$ & $16(13.4 \%)$ & $11(39.3 \%)$ & $34(16.7 \%)$ & $27(16.5 \%)$ & $7(17.9 \%)$ \\
\hline \multicolumn{7}{|c|}{ Pre-ripening cervical characteristics, n (\%) } \\
\hline Dilatation $\leq 1 \mathrm{~cm}$ & $138(93.9 \%)$ & $114(95.8 \%)$ & $24(85.7 \%)$ & $191(94.1 \%)$ & $154(93.9 \%)$ & $37(94.9 \%)$ \\
\hline Effacement $\leq 50 \%$ & $140(95.2 \%)$ & $114(95.8 \%)$ & $26(92.9 \%)$ & $195(96.1 \%)$ & $157(95.7 \%)$ & $38(97.4 \%)$ \\
\hline $\begin{array}{l}\text { Gestational age [weeks]\# } \\
\text { Mean (SD) } \\
\text { Median (Q1-Q3) }\end{array}$ & $\begin{array}{l}40.1(1.0)^{*} \\
40.0(40.0-41.0)\end{array}$ & $\begin{array}{l}40.1(1.0) \\
40.0(40.0-41.0)\end{array}$ & $\begin{array}{l}40.1(1.0) \\
40.0(40.0-41.0)\end{array}$ & $\begin{array}{l}39.6(1.4) \\
40.0(39.0-41.0)\end{array}$ & $\begin{array}{l}39.6(1.3) \\
40.0(39.0-41.0)\end{array}$ & $\begin{array}{l}39.3(1.6) \\
40.0(38.0-40.0)\end{array}$ \\
\hline $\begin{array}{l}\text { Estimated birth weight [g] } \\
\text { Mean (SD) } \\
\text { Median (Q1-Q3) }\end{array}$ & $\begin{array}{l}{[n=54]} \\
3553.6(49.8) \\
3615.5 \\
(3241.3-3868.8)\end{array}$ & $\begin{array}{l}{[n=48]} \\
3554.6(416.3) \\
3607.5 \\
(3257.5-3874.3)\end{array}$ & $\begin{array}{l}{[n=6]} \\
3545.7(388.6) \\
3653.0 \\
(3115.0-3875.0)\end{array}$ & $\begin{array}{l}{[n=54]} \\
3529.2(514.6) \\
3662.5 \\
(3300.0-3862.5)\end{array}$ & $\begin{array}{l}{[n=47]} \\
3536.7(510.2) \\
3671.0 \\
(3358.0-3855.0)\end{array}$ & $\begin{array}{l}{[n=7]} \\
3478.1(583.0) \\
3300.0 \\
(3262.0-3975.0)\end{array}$ \\
\hline
\end{tabular}

${ }^{*} \mathrm{p}<0.05$ by the Shapiro-Wilk test for normal distribution; \#at a time of administration of the first dose of the drug

Interestingly, there were no significant differences observed between investigated drugs in the duration of the $1^{\text {st }}, 2^{\text {nd }}$, and $3^{\text {rd }}$ stage of labor. The effect of age was noticed in the dinoprostone group only (Tab. 5).

Finally, neonatal outcomes were analyzed. In the Apgar score analyses the only statistically significant difference was found in the group of mothers with a disease treated by misoprostol, as in this group older $(35+)$ mothers delivered babies with lower Apgar scores on average $(9.0$ vs 9.7 pts, $\mathrm{p}<0.001)$ and additionally, significantly higher proportion of babies with a score of $\leq 6$ (7.4\% vs $2.2 \%)$ and Apgar $7-8(22.2 \%$ vs $3.3 \%)$ was observed (Tab. 6).

\section{DISCUSSION}

The comorbidities in a pregnant woman, like hypertension, diabetes mellitus, alloimmune disease, intrahepatic cholestasis or renal disease, may be a serious medical conditions influencing a wellbeing of a woman and her baby. The states mentioned are often indications for a labour induction. The several national obstetrical associations have established recommendations for most common diseases pointing out the need of the elective and active management before the due date at 40 weeks of gestation in order to reduce the perinatal and maternal risk [13,17-19]. There is still an open question, however, about the best (the saf- 
Table 2. Clinical characteristics of the study "ITT misoprostol group" across study participants

\begin{tabular}{|c|c|c|c|c|c|c|}
\hline & \multicolumn{3}{|c|}{ No concomitant disease } & \multicolumn{3}{|c|}{ Any concomitant disease } \\
\hline & $\begin{array}{l}\text { Whole group } \\
{[n=93]}\end{array}$ & $\begin{array}{l}\text { Mothers < } 35 \text { y } \\
{[n=73]}\end{array}$ & $\begin{array}{l}\text { Mothers } 35+ \\
{[n=20]}\end{array}$ & $\begin{array}{l}\text { Whole group } \\
{[n=117]}\end{array}$ & $\begin{array}{l}\text { Mothers < } 35 \text { y } \\
{[n=90]}\end{array}$ & $\begin{array}{l}\text { Mothers } 35+ \\
{[n=27]}\end{array}$ \\
\hline $\begin{array}{l}\text { Maternal age [years] } \\
\text { Mean (SD) } \\
\text { Median (Q1-Q3) }\end{array}$ & $\begin{array}{l}31.1(4.4)^{*} \\
31.0(28.5-34.0)\end{array}$ & $\begin{array}{l}29.5(3.4) \\
30.0(28.0-32.0)\end{array}$ & $\begin{array}{l}36.8(2.5) \\
36.0(35.0-38.0)\end{array}$ & $\begin{array}{l}30.8(4.0) \\
31.0(28.0-34.0)\end{array}$ & $\begin{array}{l}29.2(3.0) \\
29.0(27.0-31.3)\end{array}$ & $\begin{array}{l}36.1(1.4) \\
36.0(35.0-37.0)\end{array}$ \\
\hline $\begin{array}{l}\text { Weight at admission [kg] } \\
\text { Mean (SD) } \\
\text { Median (Q1-Q3) }\end{array}$ & $\begin{array}{l}{[n=47]^{*}} \\
76.8(10.9) \\
75.0(69.0-83.0)\end{array}$ & $\begin{array}{l}{[n=34]} \\
76.6(10.9) \\
75.0(68.8-83.0)\end{array}$ & $\begin{array}{l}{[n=13]} \\
77.4(11.4) \\
73.0(70.0-84.5)\end{array}$ & $\begin{array}{l}{[n=66]} \\
84.2(16.2) \\
83.0(71.5-93.3)\end{array}$ & $\begin{array}{l}{[n=46]} \\
86.6(16.5) \\
85.0(75.8-94.5)\end{array}$ & $\begin{array}{l}{[n=20]} \\
78.6(14.2) \\
77.0(70.0-88.5)\end{array}$ \\
\hline $\begin{array}{l}\text { Height }[\mathrm{cm}] \\
\text { Mean (SD) } \\
\text { Median (Q1-Q3) }\end{array}$ & $\begin{array}{l}{[n=84]} \\
165.7(5.7) \\
166.5 \\
(162.0-170.0)\end{array}$ & $\begin{array}{l}{[n=68]} \\
166.2(5.6) \\
167.0 \\
(163.0-170.0)\end{array}$ & $\begin{array}{l}{[n=16]} \\
163.4(5.6) \\
164.5 \\
(158.5-167.8)\end{array}$ & $\begin{array}{l}{[n=110]} \\
166.9(5.7) \\
167.0 \\
(163.8-170.0)\end{array}$ & $\begin{array}{l}{[n=83]} \\
166.9(6.1) \\
167.0 \\
(162.0-170.0)\end{array}$ & $\begin{array}{l}167.0(4.3) \\
168.0 \\
(164.0-170.0)\end{array}$ \\
\hline $\begin{array}{l}\text { Body mass index at admission } \\
{\left[\mathrm{kg} / \mathrm{m}^{2}\right]} \\
\text { Mean (SD) } \\
\text { Median (Q1-Q3) }\end{array}$ & $\begin{array}{l}{[n=46]} \\
28.5(3.7)^{*} \\
27.4(25.9-30.4)\end{array}$ & $\begin{array}{l}{[n=34]} \\
28.1(3.4) \\
27.3(25.7-29.8)\end{array}$ & $\begin{array}{l}{[n=12]} \\
29.7(4.2) \\
29.3(26.1-31.7)\end{array}$ & $\begin{array}{l}{[n=66]} \\
30.2(5.4) \\
29.9(25.9-33.4)\end{array}$ & $\begin{array}{l}{[n=46]} \\
31.0(5.5) \\
30.5(27.3-33.8)\end{array}$ & $\begin{array}{l}{[n=20]} \\
28.4(4.6) \\
27.6(24.6-31.8)\end{array}$ \\
\hline \multicolumn{7}{|l|}{ Number of pregnancies, $\mathrm{n}(\%)$} \\
\hline 1 & $52(55.9 \%)$ & $45(61.6 \%)$ & $7(35.5 \%)$ & $74(63.2 \%)$ & $58(64.4 \%)$ & $16(59.3 \%)$ \\
\hline 2 & $20(21.5 \%)$ & $16(21.9 \%)$ & $4(20.0 \%)$ & $23(19.7 \%)$ & $17(18.9 \%)$ & $6(22.2 \%)$ \\
\hline$\geq 3$ & $21(22.6 \%)$ & $12(16.4 \%)$ & $9(45.0 \%)$ & $20(17.1 \%)$ & $15(16.7 \%)$ & $5(18.5 \%)$ \\
\hline \multicolumn{7}{|c|}{ Parity history (current delivery included), $n$ (\%) } \\
\hline 1 & $64(68.8 \%)$ & $54(74.0 \%)$ & $10(50.0 \%)$ & $95(81.2 \%)$ & $75(83.3 \%)$ & $20(74.1 \%)$ \\
\hline 2 & $18(19.4 \%)$ & $14(19.2 \%)$ & $4(20.0 \%)$ & $17(14.5 \%)$ & $12(13.3 \%)$ & $5(18.5 \%)$ \\
\hline$\geq 3$ & $11(11.8 \%)$ & $5(6.8 \%)$ & $6(30.0 \%)$ & $5(4.3 \%)$ & $3(3.3 \%)$ & $2(7.4 \%)$ \\
\hline Nulliparous, n (\%) & $62(66.7 \%)$ & $53(72.6 \%)$ & $9(45.0 \%)$ & $88(75.2 \%)$ & $70(77.8 \%)$ & $18(66.7 \%)$ \\
\hline \multicolumn{7}{|l|}{ Miscarriage history $(n, \%)$} \\
\hline no & $70(75.3 \%)$ & $57(78.1 \%)$ & $13(65.0 \%)$ & $89(76.1 \%)$ & $67(74.4 \%)$ & $22(81.5 \%)$ \\
\hline yes & $23(24.7 \%)$ & $16(21.9 \%)$ & $7(35.0 \%)$ & $28(23.9 \%)$ & $23(25.6 \%)$ & $5(18.5 \%)$ \\
\hline \multicolumn{7}{|c|}{ Pre-ripening cervical characteristics, n (\%) } \\
\hline Dilatation $\leq 1 \mathrm{~cm}$ & $86(92.5 \%)$ & $69(94.5 \%)$ & $17(85.0 \%)$ & $108(92.3 \%)$ & $83(92.2 \%)$ & $25(92.6 \%)$ \\
\hline Effacement $\leq 50 \%$ & 85 (91.4\%) & $67(91.8 \%)$ & $18(90.0 \%)$ & $112(95.7 \%)$ & $85(94.4 \%)$ & $27(100.0 \%)$ \\
\hline $\begin{array}{l}\text { Gestational age [weeks]\# } \\
\text { Mean (SD) } \\
\text { Median (Q1-Q3) }\end{array}$ & $\begin{array}{l}39.7(1.8)^{*} \\
40.6(38.9-40.9)\end{array}$ & $\begin{array}{l}39.4(1.8) \\
40.0(39.0-41.0)\end{array}$ & $\begin{array}{l}38.9(1.8) \\
40.0(37.3-40.0)\end{array}$ & $\begin{array}{l}38.9(2.0) \\
40.0(38.0-40.0)\end{array}$ & $\begin{array}{l}39.0(2.0) \\
40.0(38.0-40.0)\end{array}$ & $\begin{array}{l}38.6(2.0) \\
39.0(38.0-40.0)\end{array}$ \\
\hline $\begin{array}{l}\text { Estimated birth weight [g] } \\
\text { Mean (SD) } \\
\text { Median (Q1-Q3) }\end{array}$ & $\begin{array}{l}{[n=54]} \\
3325.0(552.1)^{*} \\
3450.0 \\
(3000.0-3747.8)\end{array}$ & $\begin{array}{l}{[n=43]} \\
3375.4(513.2) \\
3456.0 \\
(3075.0-3800.0)\end{array}$ & $\begin{array}{l}{[n=11]} \\
3127.9(675.1) \\
3250.0 \\
(2800.0-3500.0)\end{array}$ & $\begin{array}{l}{[n=59]} \\
3288.5(608.6) \\
3400.0 \\
(2922.0-3786.0)\end{array}$ & $\begin{array}{l}{[n=49]} \\
3302.0(576.3) \\
3400.0 \\
(2939.0-3758.0)\end{array}$ & $\begin{array}{l}3222.4(780.7) \\
3414.5 \\
(2446.3-3850.0)\end{array}$ \\
\hline
\end{tabular}

${ }^{*} p<0.05$ by the Shapiro-Wilk test for normal distribution; \#at a time of administration of the first dose of the drug

est, and effectively leading to vaginal birth) way of a labour induction in a specific clinical situation. Several of observational studies have suggested that induction of labour at term is associated with reduction of perinatal mortality and morbidity and maternal complications [20] without increasing the Caesarean rate risk [21-22].

In our investigation we tried to reveal whether one of the two prostaglandins, dinoprostone or misoprostol, preponderate the other considering effectiveness and safety in high-risk pregnancy. Our study showed statistically important differences in Caesarean section rate and time intervals from drug implementation to delivery between groups. Our findings, however, are difficult to compare with other results, as, by our knowledge, there are no such studies published. The study investigated pregnancies with different kinds of complications presented that misoprostol usage in a group of small-for-gestational age neonates at delivery was not associated with an increased risk of Caesarean section when compared with dinoprostone or Foley catheter preinduction. The authors concluded then, that all investigated cervical ripening agents had similar efficacy and safety in small-for-gestational age pregnancies which is not in consistence with our results [23]. On the other hand, literature data indicate an increased risk of Caesarean sec- 


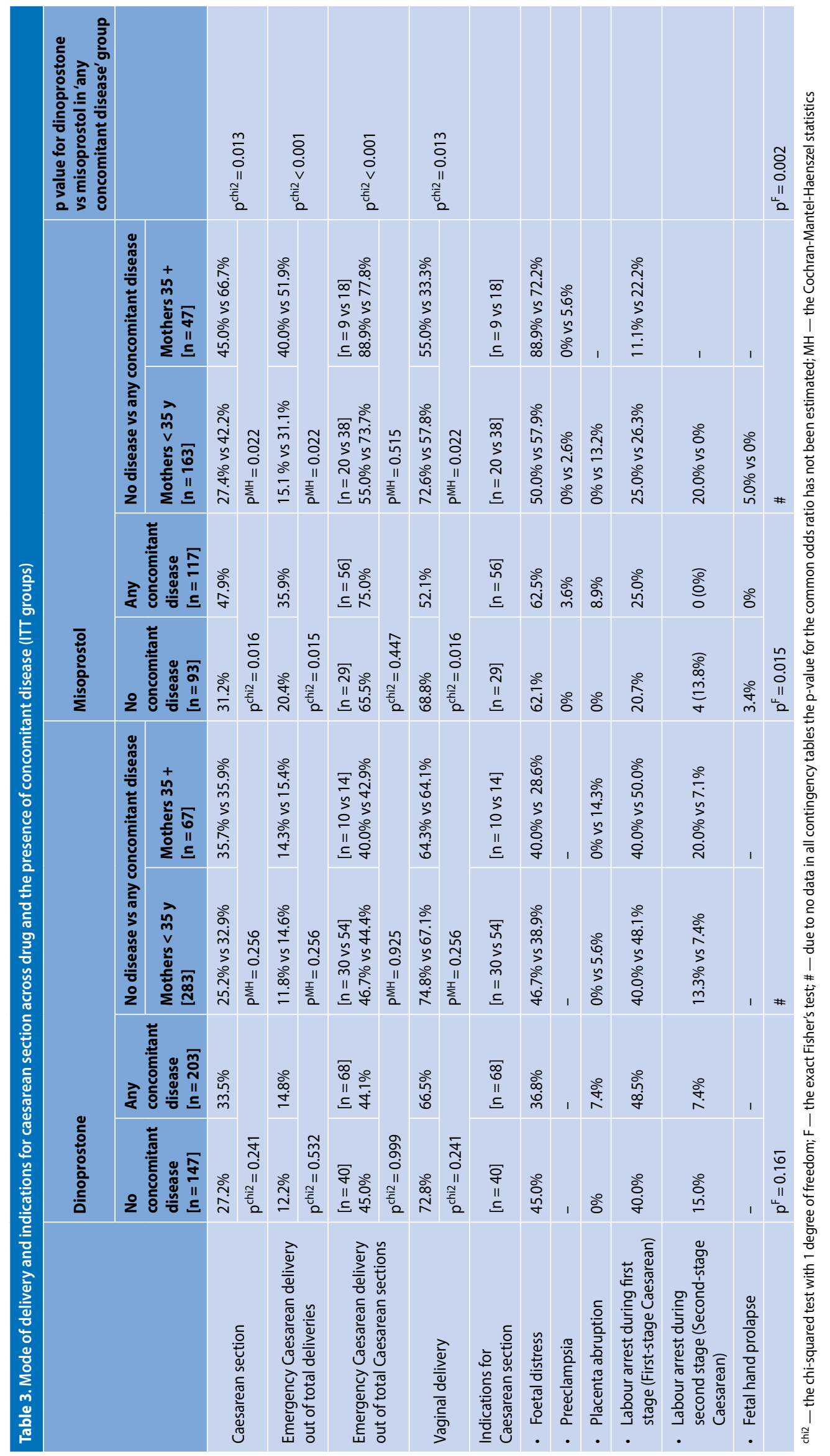




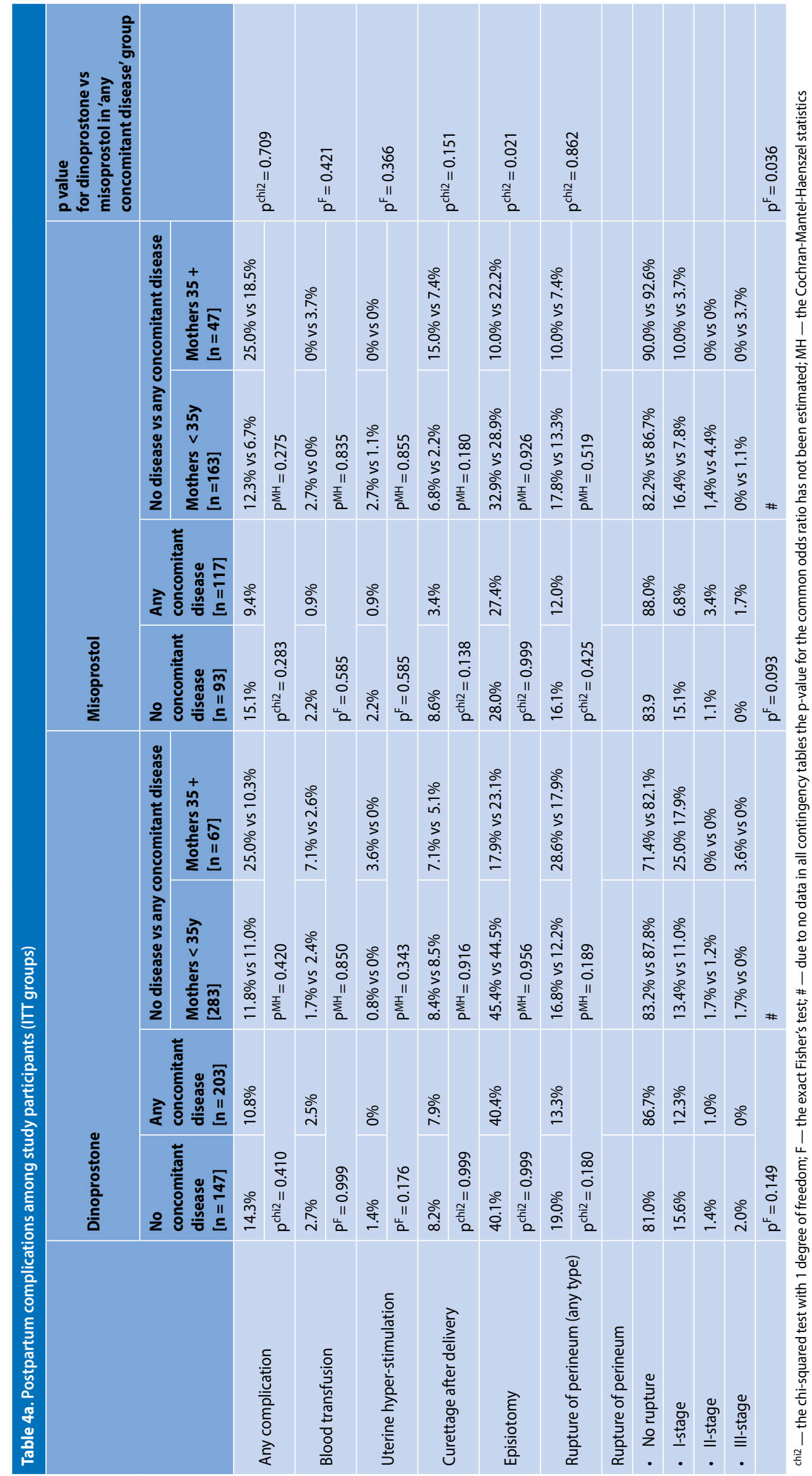


Table 4b. Postpartum complications among study participants in the group receiving both drugs (i.e. dinoprostone and misoprostol)

\begin{tabular}{|c|c|c|c|c|}
\hline & \multicolumn{4}{|c|}{ Dinoprostone followed by misoprostol } \\
\hline & \multirow{2}{*}{$\begin{array}{l}\text { No concomitant disease } \\
{[n=39]}\end{array}$} & \multirow{2}{*}{$\begin{array}{l}\text { Any concomitant disease } \\
{[n=61]}\end{array}$} & \multicolumn{2}{|c|}{ No disease vs any concomitant disease } \\
\hline & & & Mothers < 35 y $[n=89]$ & Mothers $35+[n=11]$ \\
\hline \multirow{2}{*}{ Any complication } & $23.1 \%$ & $16.4 \%$ & $15.2 \%$ vs $14.3 \%$ & $66.7 \%$ vs $40.0 \%$ \\
\hline & \multicolumn{2}{|l|}{$\mathrm{p}^{\mathrm{chi2}}=0.282$} & \multicolumn{2}{|l|}{$\mathrm{PMH}=0.824$} \\
\hline \multirow{2}{*}{ Blood transfusion } & $5.1 \%$ & $4.9 \%$ & $3.0 \%$ vs $3.6 \%$ & $16.7 \%$ vs $20.0 \%$ \\
\hline & \multicolumn{2}{|l|}{$\mathrm{PF}=0.999$} & \multicolumn{2}{|l|}{$\mathrm{P}^{\mathrm{MH}}=0.780$} \\
\hline \multirow{2}{*}{ Uterine hyper-stimulation } & $5.1 \%$ & $0 \%$ & $3.0 \%$ vs $0 \%$ & $16.7 \%$ vs $0 \%$ \\
\hline & \multicolumn{2}{|l|}{$P F=0.150$} & \multicolumn{2}{|l|}{$\mathrm{PMH}^{\mathrm{MH}}=0.400$} \\
\hline \multirow{2}{*}{ Curettage after delivery } & $7.7 \%$ & $9.8 \%$ & $9.1 \%$ vs $10.7 \%$ & $0 \%$ vs $0 \%$ \\
\hline & \multicolumn{2}{|l|}{$P F=0.999$} & \multicolumn{2}{|l|}{$\mathrm{P}^{\mathrm{MH}}=0.906$} \\
\hline \multirow{2}{*}{ Episiotomy } & $43.6 \%$ & $37.7 \%$ & $48.5 \%$ vs $41.1 \%$ & $16.7 \%$ vs $0 \%$ \\
\hline & \multicolumn{2}{|l|}{$\mathrm{p}^{\text {chi2 }}=0.676$} & \multicolumn{2}{|l|}{$\mathrm{PMH}=0.521$} \\
\hline \multirow{2}{*}{$\begin{array}{l}\text { Rupture of perineum (any } \\
\text { type) }\end{array}$} & $10.3 \%$ & $14.8 \%$ & $9.1 \%$ vs $14.3 \%$ & $16.7 \%$ vs $20.0 \%$ \\
\hline & \multicolumn{2}{|l|}{$\mathrm{p}^{\mathrm{chi2}}=0.561$} & \multicolumn{2}{|l|}{$\mathrm{PMH}=0$} \\
\hline \multicolumn{5}{|l|}{ Rupture of perineum } \\
\hline No rupture & $89.7 \%$ & $85.2 \%$ & $90.9 \%$ vs $85.7 \%$ & $83.3 \%$ vs $80.0 \%$ \\
\hline I-stage & $7.7 \%$ & $13.1 \%$ & $9.1 \%$ vs $12.5 \%$ & $0 \%$ vs $20.0 \%$ \\
\hline II-stage & $0 \%$ & $1.6 \%$ & $0 \%$ vs $1.8 \%$ & $0 \%$ vs $0 \%$ \\
\hline \multirow[t]{2}{*}{ III-stage } & $2.6 \%$ & $0 \%$ & $0 \%$ vs $0 \%$ & $16.7 \%$ vs $0 \%$ \\
\hline & \multicolumn{2}{|l|}{$\mathrm{PF}^{\mathrm{F}}=0.471$} & \multicolumn{2}{|l|}{ \# } \\
\hline
\end{tabular}

chi2 — the chi-squared test with 1 degree of freedom; F — the exact Fisher's test; \# — due to no data in all contingency tables the $\mathrm{p}$-value for the common odds ratio has not been estimated; $\mathrm{MH}$ - the Cochran-Mantel-Haenszel statistics

tion in women with pre-eclampsia in the dinoprostone induced labour group, regardless of the number of deliveries and gestational age, but no differences were found in the group with hypertension without pre-eclampsia and in the group without hypertensive diseases at all [24]. This is in conformity with our data showing no differences according to presence of concomitant disease in dinoprostone group. There were also no differences in the risk of Caesarean section, depending on the gestational age in the dinoprostone induced group of women with gestational hypertension [25]. In view of these results, we speculate that the higher rate of Caesarean rate in the misoprostol group might be related to the comorbidity of pregnant women with no such effect in the dinoprostone group.

No differences were found in perinatal outcomes when misoprostol was used in the groups with and without hypertensive diseases [26] as well as the dinoprostone insert did not adversely affect the perinatal outcomes compared to the group of women with spontaneous or oxytocin-stimulated delivery in the group of women with hypertension [27]. In our study, only babies in the subgroup of mothers over 35 years old with any concomitant disease had statistically significant lower average Apgar scores comparing with younger mothers with comorbidities. These findings require more detailed analyses on larger study groups. Regarding the neonatal safety of a preinduction of a labour in a pregnancy with any comorbidity, because only the Apgar points at the first minute were assessed, we cannot draw a definite conclusion. Nevertheless, the data we have gained show no differences in Apgar score between dinoprostone and misoprostol in any concomitant disease groups.

In our study we did not find significant differences in postpartum complications among pregnant women with any concomitant disease after labour induction using either dinoprostone or misoprostol, what is similar to other retrospective study concerning the induction of labour in hypertensive and normotensive patients with misoprostol and dinoprostone vaginal inserts. The authors also showed no differences in time to achieve active labour or to overall delivery when considering such confounding variables as BMI, gestational age, Bishop's scale or the time from drug administration to the active phase of labour [28]. Nevertheless, they showed that women with hypertension need more time to achieve active labour or overall delivery both in misoprostol and dinoprostone groups. Similarly, it has been proven that pregnant women with diabetes need more time to maturation of the cervix measured by the Bishop scale and simply need a longer time to reach the active stage of 


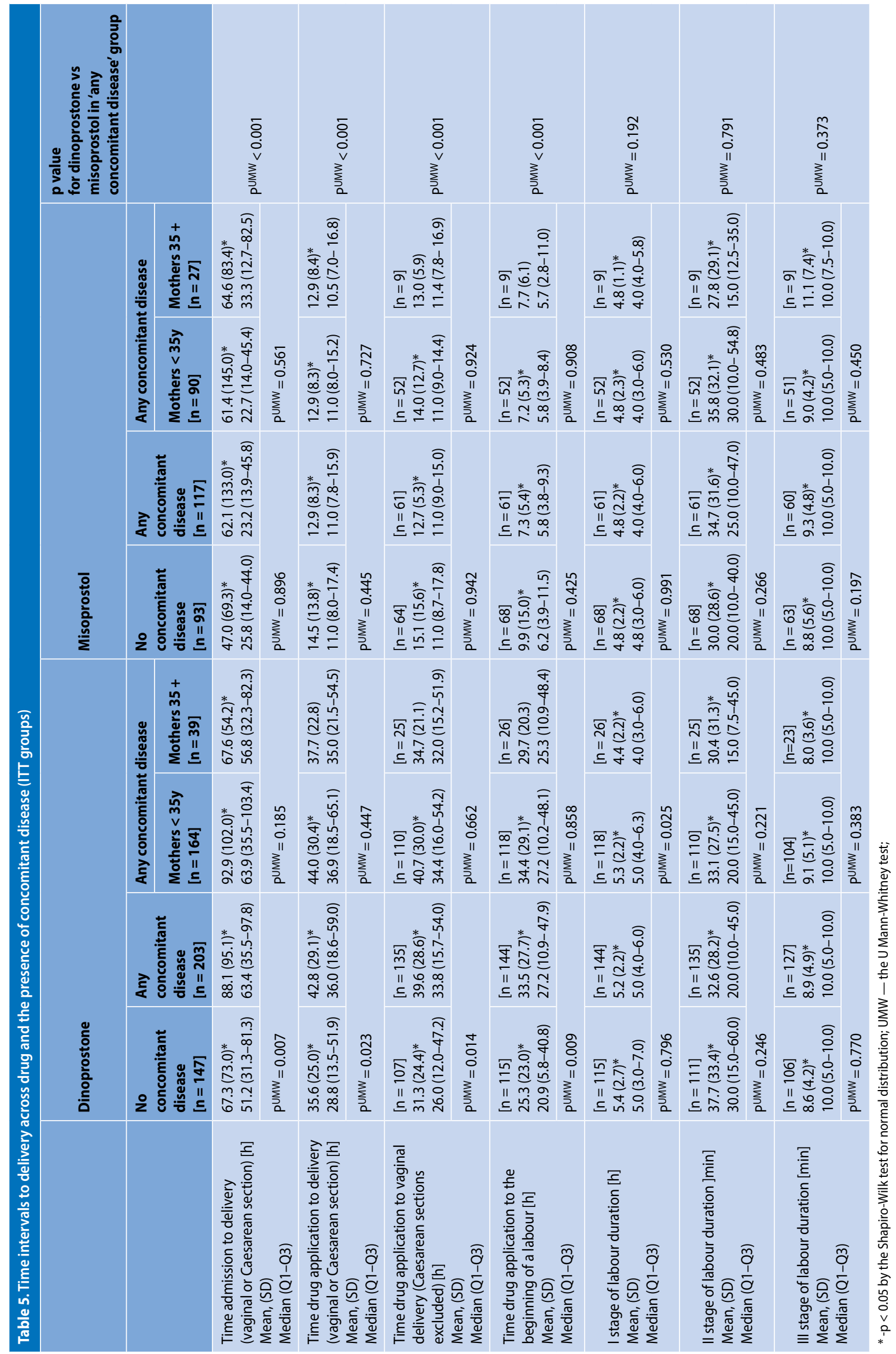




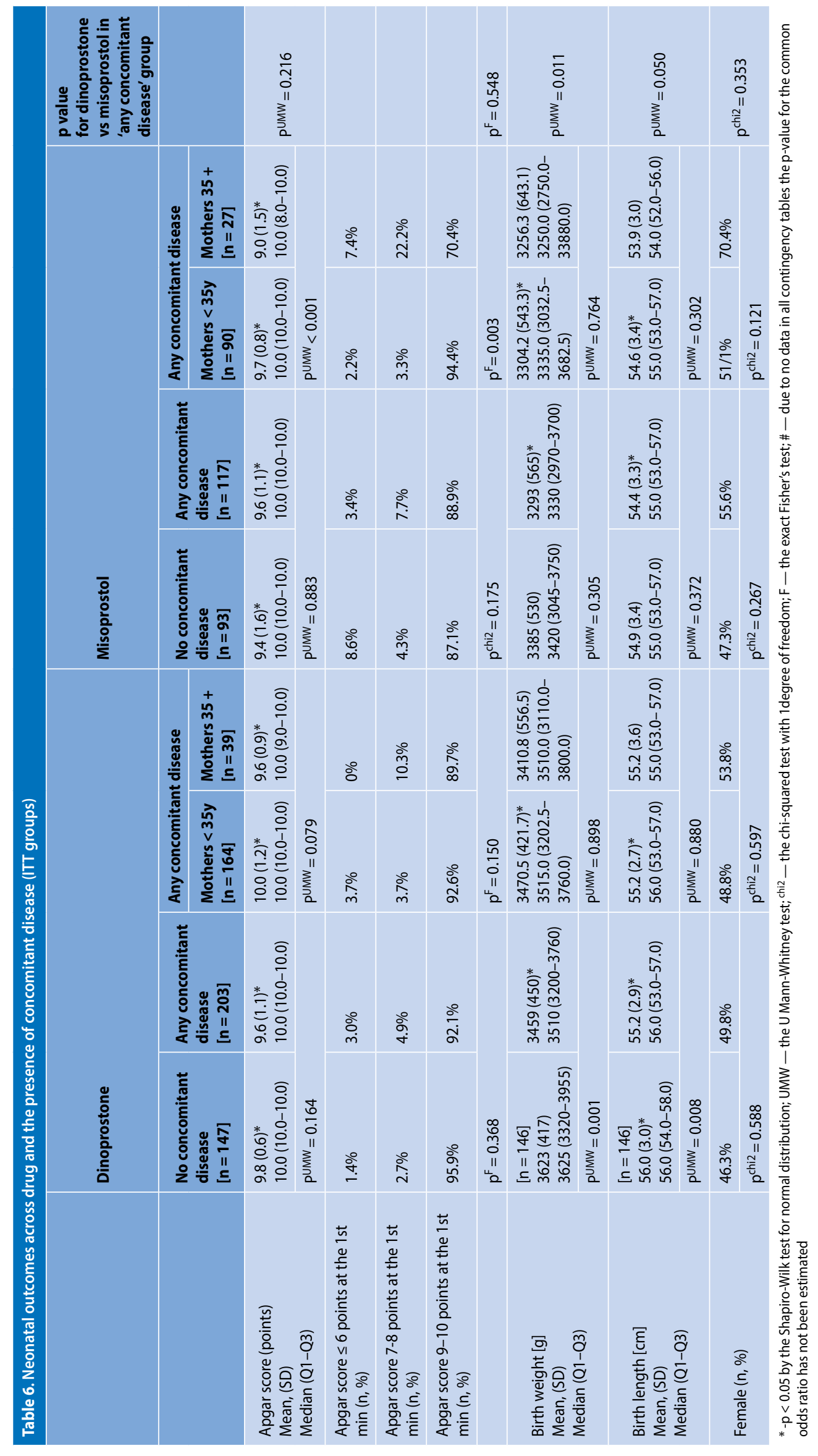


a labor, but without differences in its duration. The study also showed that women with diabetes needed a statistically significant longer time to give birth after administration of prostaglandins when compared to women without diabetes regardless the prostaglandin used [29]. Both cited studies are partially in agreement to our study showing pregnant women with any concomitant disease need statistically more time from drug application to the beginning of labour or to the delivery in dinoprostone preinduction group with the opposite, but not statistically important, observations in misoprostol group. The present analysis of women with comorbidities undergoing labour preinduction using misoprostol vaginal inserts showed strong statistical differences in time intervals from drug implementation to active phase achievement and to delivery when comparing with dinoprostone gel. That may lead to the conclusion of obtaining a faster effect of misoprostol used in the group of pregnant women with concomitant diseases.

Our study has several strengths, as the access to the data enables us to analyze a fair number of pregnant women, which increases the power of the study, the analysis of clinical data using cohort retrospective design provided an opportunity to assess effectiveness rather than efficacy, but in that way provided information on how the investigated treatments lead to the effect in real clinical practice. Next, we were able to analyze the clinical features of mothers and her babies which provided information on safety. An additional benefit is the ability to analyze the effects across the mother's age categories.

The provided results however are not free from some limitations, as mothers with a disease were investigated as one group, but the group was represented by different comorbidities. Primarily, we believed, that our investigation would be able to answer whether there is an effect of concomitant diabetes or hypertension in pregnancy on the pregnancy outcomes if labour induction took place, but due to the limited number of women with these comorbidities, we could not provide reliable answers. Additionally, our study is a retrospective cohort which, due to lack of randomization, may be a source of bias.

\section{CONCLUSIONS}

The presented study has shown that concomitant disease during pregnancy may have an impact on some safety and effectiveness outcomes. Pregnant women with a disease compared to healthy ones had higher risk of Caesarean section if were treated by misoprostol, however, this effect was not observed for dinoprostone. On the other side, the presence of a disease caused the time between drug implementation and delivery was longer if dinoprostone was used. Dinoprostone was also more beneficial than mis- oprostol to get vaginal delivery if these two drugs were compared exclusively in the group of mothers with a disease. Considering child's health, the presence of a disease and mother's age over 35 was associated with lower Apgar scores if preinduction method was by misoprostol.

Although, our results are novel in this area, and require further investigation, we believe, they may help clinicians to make better clinical decisions even at this stage of research.

\section{Acknowledgments}

Not applicable.

\section{Conflict of interest}

The authors declare no conflict of interest.

\section{Funding}

The authors receive no financial support for the study conduct.

\section{REFERENCES}

1. Jacobsson Bo, Ladfors L, Milsom I. Advanced maternal age and adverse perinatal outcome. Obstet Gynecol. 2004; 104(4): 727-733, doi: 10.1097/01.AOG.0000140682.63746.be, indexed in Pubmed: 15458893.

2. Birukov A, Herse F, Nielsen $\mathrm{JH}$, et al. Blood Pressure and angiogenic markers in pregnancy: contributors to pregnancy-induced hypertension and offspring cardiovascular risk. Hypertension. 2020; 76(3): 901-909, doi: 10.1161/HYPERTENSIONAHA.119.13966, indexed in Pubmed: 32507044.

3. Turner $\mathrm{K}$, Hameed AB. Hypertensive disorders in pregnancy current practice review. Curr Hypertens Rev. 2017; 13(2): 80-88, doi: 10.2174/1 573402113666170529110024, indexed in Pubmed: 28554307.

4. Magee LA, Pels A, Helewa M, et al. Canadian hypertensive disorders of pregnancy HDP working group. The hypertensive disorders of pregnancy. . Best Pract Res Clin Obstet Gynaecol. 2015; 29(5): 643-57.

5. Vest $A R$, Cho LS. Hypertension in pregnancy. Curr Atheroscler Rep. 2014; 16(3): 395, doi: 10.1007/s11883-013-0395-8, indexed in Pubmed: 24477794.

6. Koopmans CM, Bijlenga D, Groen H, et al. HYPITAT study group. Induction of labour versus expectant monitoring for gestational hypertension or mild pre-eclampsia after 36 weeks' gestation (HYPITAT): a multicentre, open-label randomised controlled trial. Lancet. 2009; 374(9694): 979-988, doi: 10.1016/S0140-6736(09)60736-4, indexed in Pubmed: 19656558.

7. Hutcheon JA, Lisonkova S, Magee LA, et al. Optimal timing of delivery in pregnancies with pre-existing hypertension. BJOG. 2011; 118(1): 49-54, doi: 10.1111/j.1471-0528.2010.02754.x, indexed in Pubmed: 21054760.

8. Goldenberg RL, McClure EM, Harrison MS, et al. Diabetes during Pregnancy in Low- and Middle-Income Countries. Am J Perinatol. 2016; 33(13): 1227-1235, doi: 10.1055/s-0036-1584152, indexed in Pubmed: 27182990.

9. Poston L, Caleyachetty R, Cnattingius S, et al. Preconceptional and maternal obesity: epidemiology and health consequences. Lancet Diabetes Endocrinol. 2016; 4(12): 1025-1036, doi: 10.1016/S2213-8587(16)302170 , indexed in Pubmed: 27743975.

10. Yao R, Ananth CV, Park BoY, et al. Perinatal Research Consortium. Obesity and the risk of stillbirth: a population-based cohort study. Am J Obstet Gynecol. 2014; 210(5): 457.e1-457.e9, doi: 10.1016/j.ajog.2014.01.044, indexed in Pubmed: 24674712.

11. Kulshrestha $\mathrm{V}$, Agarwal N. Maternal complications in pregnancy with diabetes. J Pak Med Assoc. 2016; 66(9 Suppl 1): S74-S77, indexed in Pubmed: 27582159.

12. Catalano PM, Mclntyre HD, Cruickshank JK, et al. HAPO Study Cooperative Research Group. The hyperglycemia and adverse pregnancy outcome study: associations of GDM and obesity with pregnancy outcomes. Diabetes Care. 2012; 35(4): 780-786, doi: 10.2337/dc11-1790, indexed in Pubmed: 22357187. 
13. Bomba-Opoń D, Drews $\mathrm{K}$, Huras $\mathrm{H}$, et al. Polish Gynecological Society Recommendations for Labor Induction. Ginekol Pol. 2017; 88(4): 224-234, doi: 10.5603/GP.a2017.0043, indexed in Pubmed: 28509326.

14. Joseph KS, Allen AC, Dodds $L$, et al. The perinatal effects of delayed childbearing. Obstet Gynecol. 2005; 105(6): 1410-1418, doi: 10.1097/01. AOG.0000163256.83313.36, indexed in Pubmed: 15932837.

15. Bishop EH. Pelvic scoring for elective inducion. Obstet Gynecol. 1964; 24: 266-268.

16. Huras $H$, Radoń-Pokracka M, Górnisiewicz $T$, et al. Induction of labor in the light of the current literature] Ginekol. Położ. Ginekol Położ. 2016; 11(1): 21-25.

17. ACOG Practice Bulletin No. 107: Induction of labor. Obstet Gynecol. 2009; 114(2 Pt 1): 386-397, doi: 10.1097/AOG.0b013e3181b48ef5, indexed in Pubmed: 19623003.

18. Leduc D, Biringer A, Lee $L$, et al. Induction of Labour. Journal of Obstetrics and Gynaecology Canada. 2013; 35(9): 840-857, doi: 10.1016/s17012163(15)30842-2.

19. Brown MA, Magee LA, Kenny LC, et al. International Society for the Study of Hypertension in Pregnancy (ISSHP). The hypertensive disorders of pregnancy: ISSHP classification, diagnosis \& management recommendations for international practice. Pregnancy Hypertens. 2018; 13: 291-310, doi: 10.1016/j.preghy.2018.05.004, indexed in Pubmed: 29803330.

20. Gibson KS, WatersTP, Bailit JL. Maternal and neonatal outcomes in electively induced low-risk term pregnancies. Am J Obstet Gynecol. 2014; 211(3): 249. e1-249.e16, doi: 10.1016/j.ajog.2014.03.016, indexed in Pubmed: 24631440.

21. Stock SJ, Ferguson E, Duffy A, et al. Outcomes of elective induction of labour compared with expectant management: population based study. BMJ. 2012; 344: e2838, doi: 10.1136/bmj.e2838, indexed in Pubmed: 22577197.

22. Souter V, Painter I, Sitcov K, et al. Maternal and newborn outcomes with elective induction of labor at term. Am J Obstet Gynecol. 2019;
220(3): 273.e1-273.e11, doi: 10.1016/j.ajog.2019.01.223, indexed in Pubmed: 30716284

23. Rossi RM, Warshak CR, Masters HR, et al. Comparison of prostaglandin and mechanical cervical ripening in the setting of small for gestational age neonates. J Matern Fetal Neonatal Med. 2019; 32(22): 3841-3846, doi: 10.1080/14767058.2018.1474873, indexed in Pubmed: 29739262.

24. Ferrazzani S, De Santis L, Carducci B, et al. Prostaglandin: cervical ripening in hypertensive pregnancies. Acta Obstet Gynecol Scand. 2003; 82(6): 510-515, doi: 10.1034/j.1600-0412.2003.00143.x, indexed in Pubmed: 12780421.

25. Durst JK, Subramaniam A, Tang Y, et al. Mode of delivery in nulliparous women with gestational hypertension undergoing early term induction of labor. J Matern Fetal Neonatal Med. 2017; 30(19): 2291-2296, doi: 10.1080/14767058.2016.1247153, indexed in Pubmed: 27724054.

26. de Paiva Marques RM, Souza AS, de Lucena Feitosa FE, et al. Maternal and perinatal outcomes in women with and without hypertensive syndromes submitted to induction of labor with misoprostol. Hypertens Pregnancy. 2017; 36(1): 1-7, doi: 10.1080/10641955.2016.1197935, indexed in Pubmed: 27420285.

27. Hu YP, Zhou D, Li M, et al. Use of labor induction with dinoprostone vaginal suppositories in pregnant women with gestational hypertension. J Obstet Gynaecol Res. 2019; 45(11): 2185-2192, doi: 10.1111/jog.14092, indexed in Pubmed: 31456315

28. Sheibani L, Raymond K, Rugarn O, et al. Associations of hypertensive disorders of pregnancy and outcomes of labor induction with prostaglandin vaginal inserts. Hypertens Pregnancy. 2018; 37(1): 51-57, doi: 10.1080/10641955.2017.1420800, indexed in Pubmed: 29291357.

29. Hawkins JS, Stephenson M, Powers B, et al. Diabetes mellitus: an independent predictor of duration of prostaglandin labor induction. J Perinatol. 2017; 37(5): 488-491, doi: 10.1038/jp.2016.270, indexed in Pubmed: 28125096 